\title{
BACK PAIN AND OSTEOARTHRITIS AS SECONDARY DISABILITIES OF LOWER
} LIMB AMPUTATION

\author{
Eva Pröbsting $^{1 *}$, Andreas Kannenberg ${ }^{2}$, Siegmar Blumentritt ${ }^{3}$ \\ ${ }^{1}$ OttoBock HealthCare GmbH, Germany. \\ ${ }^{2}$ Otto Bock Healthcare LP, USA. \\ ${ }^{3}$ PFH Göttingen, Germany. \\ * Email: Eva.Proebsting@ottobock.de
}

\section{INTRODUCTION}

Long-term damages after lower extremity amputation have previously been analysed in three systematic reviews ${ }^{5-7}$ showing that amputees have a higher risk for developing knee and hip osteoarthritis on the sound side. The altered gait pattern appears to increase the load on the sound side. ${ }^{1-3}$ This paper analysed the extent to which the above described assumption is supported by the scientific literature with specific focus on the risk of developing back pain and osteoarthritis in amputees.

\section{METHODS}

A systematic literature search (EMBASE, Medline, Journal of Prosthetics and Orthotics database) was conducted for publications that had investigated changes caused by amputations. Furthermore, the references of identified publications were also scanned for pertinent publications. All suitable articles were qualitatively analyzed and the available quantitative results were summarized.

\section{RESULTS}

The search identified 20 relevant studies, ${ }^{4-23}$ reporting back pain and 14 studies, ${ }^{5-8,11,13,20,24-30}$ on osteoarthritis. The prevalence of back pain is increased for amputees in comparison to the able-bodied population. Furthermore, amputees suffer more often from clinical signs of knee and hip osteoarthritis. Nevertheless, the prevalence of radiographic signs is increased for the sound knee of the amputees. There are different reasons given in the literature for this increased risks. The altered gait ${ }^{14,17}$ and leg length discrepancies $6,11,13,20$ seems to have a big influence on the back pain. For the increased prevalence of the osteoarthritis, these parameters $6,11,27,28$ as well as hopping 28 and standing without the prosthesis ${ }^{28}$ are contributing factors.

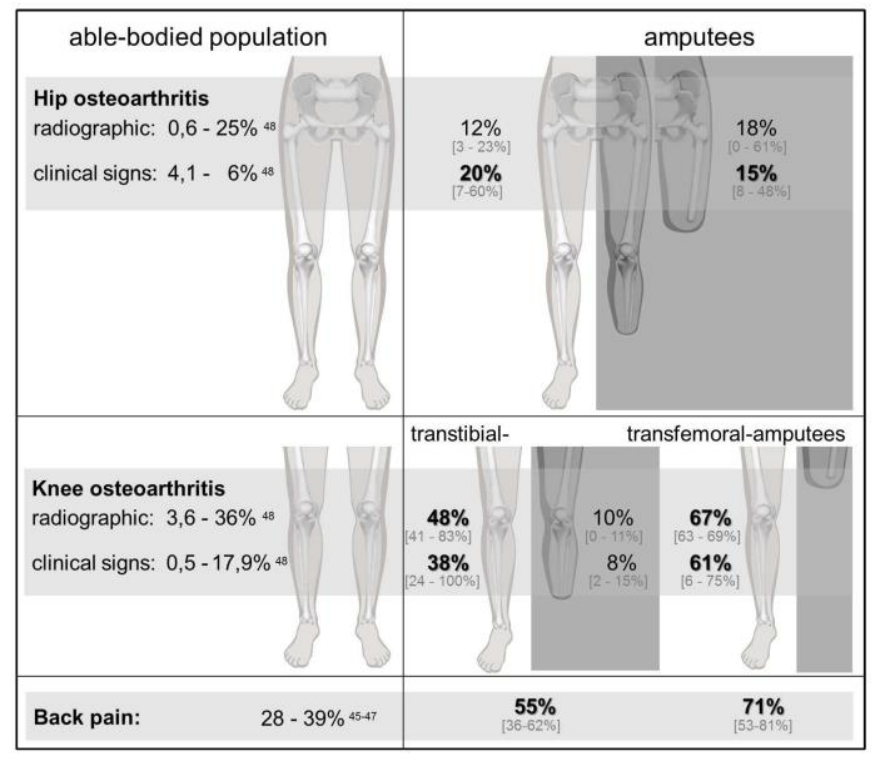

Figure 1. Quantitative summary of the prevalence of back pain and arthritis.

\section{CONCLUSION}

It may be possible to reduce the risks of back pain and osteoarthritis with novel prosthetic components and by optimising prosthetic fitting. On one hand, an optimised prosthesis will be used more regularly. On the other hand, it will be exposed to greater loads and therefore the load to the locomotor system could be distributed more evenly amongst both legs. Both aspects would result in a more physiological loading of the locomotor system.

\section{SIGNIFICANCE}

It is often assumed that leg amputations result in a greater risk of degenerative changes to the locomotor system. ${ }^{24}$ Furthermore in one-on-one interviews amputees report on their fear of these changes. Therefore, this paper analysed the potential risk of various degenerative diseases in amputees. 


\section{REFERENCES}

1. Gailey et al. Review of secondary physical conditions associated with lower-limb amputation and long-term prosthesis use. J Rehabil Res Dev; 2008;45(1):15-29. DOI: 10.1682/JRRD.2006.11.0147

2. Morgenroth DC, Gellhorn AC, Suri P. Osteoarthritis in the disabled population: a mechanical perspective. $P M R$. 2012;4(5 Suppl):S20-7. doi: 10.1016/j.pmrj.2012.01.003.

3. Robbins et al. A review of the long-term health outcomes associated with war-related amputation. Mil Med. 2009; 174(6):588-92.

4. Ehde et al. Chronic phantom sensations, phantom pain, residual limb pain, and other regional pain after lower limb amputation. Arch Phys Med Rehabil. 2000;81(8):1039-44. DOI: https://doi.org/10.1053/apmr.2000.7583

5. Mussman et al. Contralateral lower extremity evaluation with a lower limb prosthesis. J Am Podiatry Assoc. 1983 $\mathrm{Jul} ; 73(7): 344-6$.

6. Burke MJ, Roman V, Wright V. Bone and joint changes in lower limb amputees. Ann Rheum Dis. 1978 Jun; 37(3): 252 254 .

7. Ebrahimzadeh MH, Hariri S. Long-term outcomes of unilateral transtibial amputations. Mil Med. 2009;174(6):593597.

8. Ebrahimzadeh MH, Fattahi AS. Long-term clinical outcomes of Iranian veterans with unilateral transfemoral amputation. Disabil Rehabil. 2009;31(22):1873-7. DOI: $\underline{10.1080 / 09638280902810968}$

9. Ehde et al. Back pain as a secondary disability in persons with lower limb amputations. Arch Phys Med Rehabil. 2001;82(6):731-734. DOI:10.1053/apmr.2001.21962

10. Ephraim et al. Phantom pain, residual limb pain, and back pain in amputees: results of a national survey. Arch Phys Med Rehabil.2005;86(10):1910-9.

DOI: $10.1016 /$ j.apmr.2005.03.031

11. Friberg O. Biomechanical significance of the correct length of lower limb prostheses: a clinical and radiological study. Prosthet Orthot Int. 1984;8(3):124-9.

12. Friel K, Domholdt E, Smith DG. Physical and functional measures related to low back pain in individuals with lowerlimb amputation: an exploratory pilot study. J Rehabil Res Dev. 2005;42(2):155-66. DOI: 10.1682/JRRD.2004.08.0090

13. Krämer J, Heisel JM, Ullrich CH. Late results of patients with amputation of the thigh (author's transl). Z Orthop Ihre Grenzgeb. 1979;117(5):801-7.

14. Kulkarni et al. Chronic low back pain in traumatic lower limb amputees. Clin Rehabil. 2005 Jan;19(1):81-6. DOI: $10.1191 / 0269215505 \mathrm{cr} 819 \mathrm{oa}$
15. Kusljugić et al. Chronic low back pain in individuals with lower-limb amputation. Bosn J Basic Med Sci. 2006 May;6(2):67-70. DOI:10.17305/bjbms.2006.3177

16. Marshall et al. Pain site and impairment in individuals with amputation pain. Arch Phys Med Rehabil. 2002;83(8):1116-9. DOI: https://doi.org/10.1053/apmr.2002.33121

17. Morgenroth et al. The relationship between lumbar spine kinematics during gait and low-back pain in transfemoral amputees. Am J Phys Med Rehabil. 2010;89(8):635-43. DOI: 10.1097/PHM.0b013e3181e71d90

18. Morgenroth et al. Low-back pain in transfemoral amputees: is there a correlation with static or dynamic leglength discrepancy? Am J Phys Med Rehabil. 2009;88(2):10813. DOI:10.1097/PHM.0b013e318194fbbc

19. Smith et al. Phantom limb, residual limb, and back pain after lower extremity amputations. Clin Orthop Relat Res. 1999 Apr;(361):29-38.

20. Wilcke KH. Unilateral leg amputation and its surgicalorthopedic sequelae. Monatsschr Unfallheilkd Versicher Versorg Verkehrsmed. 1971;74(5):236-48.

21. Melcer et al. A Comparison of Four-Year Health Outcomes following Combat Amputation and Limb Salvage. PLOS ONE; 2017;12(2):e0173214.https://doi.org/10.1371/journal.pone.01 $\underline{70569}$

22. Devan H, Seals R. Vascular health in the ageing athlete. Exp Physiol, 2012;97.3; pp 305-310. doi: $\underline{10.1113 / \text { expphysiol.2011.058792 }}$

23. Devan $\mathrm{H}$ et al. Exploring Factors Influencing Low Back Pain in People With Nondysvascular Lower Limb Amputation: A National Survey. $P M \& R$. 2017;9, 10, 949-959. DOI: 10.1016/j.pmrj.2017.02.004

24. Lemaire ED, Fisher FR. Osteoarthritis and elderly amputee gait. Arch Phys Med Rehabil. 1994;75(10):1094-9.

25. Benichou C, Wirotius JM. Articular cartilage atrophy in lower limb amputees. Arthritis Rheum. 1982; 25,1, 80-82.

26. Hungerford DS. Early diagnosis of ischemic necrosis of the femoral head. Johns Hopkins Med J. 1975;137:270-5.

27. Kulkarni et al. Association between amputation, arthritis and osteopenia in British male war veterans with major lower limb amputations. Clin Rehabil. 1998;12(4):348-53. DOI: $10.1191 / 026921598672393611$

28. Norvell et al. The prevalence of knee pain and symptomatic knee osteoarthritis among veteran traumatic amputees and nonamputees. Arch Phys Med Rehabil. 2005;86(3):487-93. DOI:10.1016/j.apmr.2004.04.034 
29. Struyf et al. The prevalence of osteoarthritis of the intact hip and knee among traumatic leg amputees. Arch Phys Med Rehabil. 2009;90(3):440-6. doi: 10.1016/j.apmr.2008.08.220.

30. Melzer I, Yekutiel M, Sukenik S. Comparative study of osteoarthritis of the contralateral knee joint of male amputees who do and do not play volleyball. $J$ Rheumatol. 2001;28(1):169-72.

\section{DISCLOSURE}

Eva Pröbsting and Andreas Kannenberg are full time employees of the OttoBock Health Care GmbH. 